\title{
Locus of control moderates the association of COVID-19 stress and general mental distress: results of a Norwegian and a German-speaking cross-sectional survey
}

\author{
Henning Krampe ${ }^{1}$, Lars Johan Danbolt ${ }^{2,3}$, Annie Haver ${ }^{4,5}$, Gry Stålsett ${ }^{6,7}$ and Tatjana Schnell ${ }^{6,8 *}$
}

\begin{abstract}
Background: An internal locus of control (LOC I) refers to the belief that the outcome of events in one's life is contingent upon one's actions, whereas an external locus of control (LoC E) describes the belief that chance and powerful others control one's life. This study investigated whether LoC I and LoC E moderated the relationship between COVID-19 stress and general mental distress in the general population during the early months of the COVID-19 pandemic.

Methods: This cross-sectional survey study analysed data from a Norwegian $(n=1225)$ and a German-speaking sample $(n=1527)$. We measured LoC with the Locus of Control-4 Scale (IE-4), COVID-19 stress with a scale developed for this purpose, and mental distress with the Patient Health Questionnaire 4 (PHQ-4). Moderation analyses were conducted using the PROCESS macro for SPSS.

Results: The association between COVID-19 stress and general mental distress was strong $(r=.61$ and $r=.55$ for the Norwegian and the German-speaking sample, respectively). In both samples, LoC showed substantial moderation effects. LoC I served as a buffer $(p<.001)$, and LoC E exacerbated $(p<.001)$ the relation between COVID-19 stress and general mental distress.

Conclusions: The data suggest that the COVID-19 pandemic is easier to bear for people who, despite pandemicrelated strains, feel that they generally have influence over their own lives.

An external locus of control, conversely, is associated with symptoms of depression and anxiety. The prevention of mental distress may be supported by enabling a sense of control through citizen participation in policy decisions and transparent explanation in their implementation.
\end{abstract}

Keywords: Anxiety, COVID-19, Depression, Locus of control (LoC), Moderator analysis, Pandemic, PHQ-4

\footnotetext{
* Correspondence: tatjana.schnell@mf.no

${ }^{6}$ Social Sciences, MF Norwegian School of Theology, Religion and Society, Oslo, Norway

${ }^{8}$ Existential Psychology Lab, Institute of Psychology, University of Innsbruck, Innsbruck, Austria

Full list of author information is available at the end of the article
}

(c) The Author(s). 2021 Open Access This article is licensed under a Creative Commons Attribution 4.0 International License, which permits use, sharing, adaptation, distribution and reproduction in any medium or format, as long as you give appropriate credit to the original author(s) and the source, provide a link to the Creative Commons licence, and indicate if changes were made. The images or other third party material in this article are included in the article's Creative Commons licence, unless indicated otherwise in a credit line to the material. If material is not included in the article's Creative Commons licence and your intended use is not permitted by statutory regulation or exceeds the permitted use, you will need to obtain permission directly from the copyright holder. To view a copy of this licence, visit http://creativecommons.org/licenses/by/4.0/. The Creative Commons Public Domain Dedication waiver (http://creativecommons.org/publicdomain/zero/1.0/) applies to the data made available in this article, unless otherwise stated in a credit line to the data. 


\section{Background}

Numerous studies found that mental distress has substantially increased during the COVID-19 pandemic, and first systematic reviews and meta-analyses reported prevalence rates ranging from 21.8 to $33.0 \%$, from 22.0 to $33.7 \%$, and from 34.4 to $41.1 \%$, for clinically relevant anxiety, depression, and general mental distress, respectively [1-8]. Researchers observed that people experienced not only mental distress but also stress that was directly related to the pandemic and its aftermath [9, 10]. Thus, several scales were developed to measure stress specifically due to the pandemic. These COVID19 stress scales primarily assess symptoms of anxiety and fears associated with COVID-19, but also various other facets of stress experience during the pandemic, such as feeling restricted by lockdown measures, uncertainty and doubts of how to protect oneself and loved ones against infections, sleep disturbance, confusion, frustration, anger, loneliness, social isolation, and fears of the future $[11,12]$. While there is ample evidence that higher COVID-19 stress is significantly related to symptoms of mental distress [12-17], we do not know much about factors influencing this relationship. In particular, there is a need for investigations into resilience factors and resources that can buffer the effect of acute COVID-19 stress on mental distress. Research on resilience and resources will help inform public health measures and interventions to improve coping with stressful experience during the current pandemic and its aftermath, and it will provide important insights for dealing with future crises.

Until now, several factors were found to serve as resources buffering the effects of stressors, stressful experiences or risk factors on mental health or protective health promoting behaviour during the first year of the pandemic. Among these moderating factors are higher self-esteem [18], greater psychological flexibility and acceptance of difficult experience [19], higher meaning in life and self-control [12], less digital emotion contagion [20], higher age [21], male gender and lower COVID-19 stress [22], emotion regulation by cognitive reappraisal strategies [23], increased resilience [24], trust in the healthcare system [25], identifying positive over negative aspects of COVID-19 lockdown [26], as well as utilizing prenatal care services [27]. Although their stress buffering and/or resilience strengthening effects are empirically confirmed in the respective study samples, it is open to what extent the protective mechanisms of the mentioned moderators would work in other samples and across various circumstances. Research is needed to identify psychological moderators that are stable, established, and robust, so that their assumed stress-buffering effect would be less dependent on sample characteristics and regional pandemic differences.
Locus of control ( $\mathrm{LoC}$ ) is among the four most widely investigated personality traits [28]. It is a relatively stable dimension that describes the extent to which individuals are convinced to be able to control their environment and future, and to experience significant events as consequences of their own behaviour [29]. LoC covers two aspects. While external LoC refers to the belief that chance and powerful others control one's life, internal LoC describes the belief that the outcome of events in one's life is contingent upon one's actions. LoC has originally been assessed with continuous internal-external scales (e. g. [29, 30]), whereas later on, separate scales for internal and external LoC were considered more appropriate (e.g. [31-33]). Cross-sectional and longitudinal studies from various international regions found that higher internal LoC and lower external LoC were moderately associated with greater mental health, lower situational stress, and lower mental distress, like depression and anxiety [30, 34-38]. Studies on psychosocial factors during the COVID-19 pandemic also investigated the role of LoC. In a sample of 339 participants from the United States, Berg \& Lin (2020) examined predictors of the self-rated likelihood to engage in COVID-19 prevention behaviors. While internal health-related LoC did not show significant associations, external health-related LoC regarding powerful others predicted preventative behaviors [39]. Two studies examined associations of LoC and mental health. In a sample of 1723 adults from the USA and five European countries, Sigurvinsdottir et al. (2020) found significant negative correlations of internal LoC, and significant positive correlations of external LoC with depression, anxiety, and stress. Multiple regression analyses with diverse predictors showed that higher external LoC was moderately related to higher depression, anxiety and stress, while higher internal LoC was slightly related to lower depression and less stress, but not to anxiety [40]. In a sample of 667 participants from India, Alat et al. (2021) investigated the protective role of psychological resources for mental health. Higher internal LoC correlated moderately with higher positive affect and affect balance, as well as with lower negative affect and psychological distress. Using confirmatory factor analysis and path analysis, the authors found a small indirect effect indicating that affect balance mediated the association between internal LoC on psychological distress [41]. With its established validity for more than five decades, a temporal and transnational robustness, as well as replicated associations with perceived stress and mental health, LoC seems to be a promising candidate when it comes to factors that might attenuate the putative relationship between COVID-19 stress and general mental distress.

The objective of this study was therefore to investigate whether internal LoC and external LoC moderated the 
relation between COVID-19 stress and general mental distress during the early months of the COVID-19 pandemic. In order to assess the robustness of the assumed stress-buffering (LoC I) and stress-exacerbating (LoC E) effects, we collected data in a Norwegian and a Germanspeaking sample (primarily from Germany and Austria). Norway on the one hand and the central-European countries Germany and Austria on the other hand showed both differences and similarities in pandemicrelevant aspects of country and societal characteristics, as well as regarding the extent of the pandemic. Similarities existed with regard to the timing, extend, and strictness of national COVID-19 restriction guidelines [42, 43]. Differences can be seen in the following characteristics: Most importantly, population density is substantially lower in Norway, and institutional trust, as in the other Scandinavian countries, is higher than in Austria and Germany [42, 44]. According to data from the Johns Hopkins University (2021), in the first three weeks of March 2020 Norway had more cumulative confirmed COVID-19 cases per million people than Germany and Austria, but from April 1, 2020 to the end of our survey period, the number of cumulative confirmed cases per million people was always lower in Norway than in Germany and Austria [45]. The same holds for the cumulative number of confirmed COVID-19 deaths. Despite of the contextual variations, we expected that in both samples, high internal LoC would buffer, and high external LoC would exacerbate the association between COVID-19 stress and general mental distress.

\section{Methods}

This cross-sectional survey was conducted in a Norwegian sample during the weeks when the strict COVID-19 regulations were gradually eased (May, 7, 2020 to June, 4, 2020 [44]), and in a German-speaking sample during the times of strict regulations and in the weeks thereafter (Austria, Germany, April 10, 2020 to May 28, 2020 [12]). Participation was voluntary, without compensation, and could be terminated by participants anytime. Ethical approval was issued by the Review Board (Psychology) of the University of Innsbruck, No 09/2020, as well as by Personvernombudet Innlandet Hospital Trust, Norway, No 20/02104-1. All participants expressed their informed consent by explicitly agreeing to continue with the questionnaire after being informed about the study's aims, employed data protection, participants' rights, and contact points for questions or concerns.

Data were collected by means of convenience sampling, using online questionnaire tools. Invitations to the study were sent out via university, business, worldviewrelated and regional network newsletters, and posted in several newspapers and news websites.

\section{Participants}

The inclusion criteria of this study were a minimum age of 18 years, agreement to participant consent, and completion of the questionnaire. Cases with disproportionately short response times were deleted ( $n=2$ and $n=7$ for the Norwegian and the German-speaking sample). After exclusion, the total sample amounted to $N=2752$. The Norwegian sample $(n=1225)$ included mainly participants with Norwegian nationality (95.5\%) and some with Swedish (1.4\%), Danish (0.7\%), and other nationalities $(2.4 \%)$. The German-speaking sample $(n=1527)$ included participants with German (51.9\%), Austrian (37.5\%), Italian (5.8\%), and other nationalities (4.8\%). Demographic and psychological characteristics of the participants are shown in Table 1.

\section{Measures}

Locus of control (LoC) The 4-item Internal/External Locus of Control-4 Scale, IE-4, [32] was used to assess LoC. The subscales for internal LoC (LoC I) and external LoC (LoC E) consist of two items each, describing beliefs of personal control with a range from 1 (does not apply at all) to 5 (applies completely). Kovaleva et al. (2012) report extensive data on good psychometric properties of the German version, including content, factorial, and construct validity [32]: Reliabilities for two normative samples were determined by McDonald's omegas of .71 and .70 for LoC I, and of .63 and .53 for LoC E. A confirmatory factor analysis included the IE-4 and the KMKB, a German LoC scale that is based on a short version of the Levenson locus of control scale. The results showed that corresponding latent factors of both scales correlated highly between .92 and .99 . Concerning construct validity, the authors found positive correlations of the LoC I scale with self-efficacy (.61), life satisfaction (.53), optimism (.36), and persistence (.37), as well as negative correlations of the LoC E scale with self-efficacy (.32), life satisfaction (-.48), optimism $(-.32)$, and persistence $(-.22)$. In the present study, McDonald's omegas of LoC I and LoC E were .69 and .71 (Norwegian sample), and .80 and .60 (German-speaking sample). For use in the Norwegian sample, the original items were translated and a back-translation checked.

COVID-19 stress Because there were no instruments available at that time, we developed a novel scale to determine the extent of acute psychological stress due to COVID-19 [12]. After examining the relevant literature and drawing on population surveys released by the media, we generated seven items tapping a broad range of affective stress reactions (feelings of intolerability, boredom, anger, and being left alone) and fears and 
Table 1 Demographic and psychological characteristics of study participants; mean [SD]; n (\%)

\begin{tabular}{|c|c|c|c|}
\hline & $\begin{array}{l}\text { Norwegian sample } \\
n=1209-1225\end{array}$ & $\begin{array}{l}\text { German-speaking sample } \\
n=1522-1527\end{array}$ & $p$ \\
\hline Age (years) & $50.26[13.16]$ & $40.35[16.66]$ & $<.001$ \\
\hline Gender & & & $<.001$ \\
\hline Women & $897(73.20)$ & $993(65.00)$ & \\
\hline Men & $326(26.60)$ & $528(34.60)$ & \\
\hline Divers & $2(0.20)$ & $6(0.40)$ & \\
\hline Relationship status & & & $<.001$ \\
\hline Married/partnered & $683(55.80)$ & $953(62.40)$ & \\
\hline Other & $542(44.20)$ & $574(37.60)$ & \\
\hline Children & & & $<.001$ \\
\hline No & $252(20.60)$ & $975(63.90)$ & \\
\hline Yes & $971(79.40)$ & $552(36.10)$ & \\
\hline Living together status & & & .460 \\
\hline Living alone & $249(20.30)$ & $328(21.50)$ & \\
\hline Living with others & $976(79.70)$ & $1199(78.50)$ & \\
\hline Education: & & & $<.001$ \\
\hline Secondary & $19(1.60)$ & $190(12.40)$ & \\
\hline Advanced & $133(10.90)$ & $453(29.70)$ & \\
\hline University & $1073(87.60)$ & $884(57.90)$ & \\
\hline \multicolumn{4}{|l|}{ I have been infected with Sars CoV-2 } \\
\hline Yes & $14(1.10)$ & $12(0.80)$ & \\
\hline No / I do not know & $1211(98.90)$ & $1515(99.20)$ & \\
\hline A close person has been infected & & & .336 \\
\hline Yes & $136(11.10)$ & $130(8.50)$ & \\
\hline No / I do not know & $1089(88.90)$ & $1397(91.50)$ & .022 \\
\hline \multicolumn{4}{|l|}{$\operatorname{LoC}^{a)}$} \\
\hline Internal & $3.65[0.87]$ & $3.94[0.81]$ & $<.001$ \\
\hline External & $1.84[0.75]$ & $2.31[0.86]$ & $<.001$ \\
\hline COVID-19 stress ${ }^{b)}$ & $1.34[0.82]$ & 1.54 [0.89] & $<.001$ \\
\hline General mental distress ${ }^{c)}$ & $2.51[2.35]$ & $3.48[2.82]$ & $<.001$ \\
\hline \multicolumn{4}{|l|}{ Elevated general mental distress ${ }^{c}$} \\
\hline$>5$ & $111(9.10)$ & $291(19.10)$ & $<.001$ \\
\hline$>3$ & $355(29.00)$ & $628(41.10)$ & $<.001$ \\
\hline$>2$ & $551(45.00)$ & $861(56.40)$ & $<.001$ \\
\hline Depression ${ }^{c)}$ & $1.38[1.33]$ & $1.82[1.52]$ & $<.001$ \\
\hline Elevated depression (> 2) c) & $175(14.30)$ & $346(22.70)$ & $<.001$ \\
\hline Anxiety ${ }^{c)}$ & $1.12[1.28]$ & $1.66[1.57]$ & $<.001$ \\
\hline Elevated anxiety $(>2) c$ c & $123(10.00)$ & $321(21.00)$ & $<.001$ \\
\hline
\end{tabular}

a LoC measured by the IE-4 subscales LoC Internal and LoC External (range: 1-5)

${ }^{\mathrm{b}}$ Acute psychological stress due to COVID-19 measured by the COVID-19 stress scale (range: $0-5$ )

'General mental distress, depression, and anxiety measured by the PHQ-4. Total scale (range $0-12$ ) with cut-offs $>5,>3,>2$ for at least severe, moderate, and mild distress. Subscales depression (PHQ-2) and anxiety (GAD-2) (range 0-6), with cut-offs $>2$ for elevated depression and anxiety

pessimism about internal resources and the future. The items are displayed in suppl. Table 1 [Supplementary Material]. With a view to the current situation, items are rated on a six-point Likert scale ranging from 0 (strongly disagree) to 5 (strongly agree). For use in the Norwegian sample, the original items were translated and a backtranslation checked. Internal consistencies in the present study were good, with McDonald's omega coefficients of 
.81 (Norwegian sample) and .81 (German-speaking sample). Confirmatory factor analyses (CFAs) support a onedimensional model of COVID-19 stress in both samples $\left(\mathrm{X}^{2}(14)=101.83, \quad \mathrm{RMSEA}=.072, \quad \mathrm{SRMR}=.043, \mathrm{CFI}=\right.$ .943 for the Norwegian sample, and $X^{2}(14)=133.63$, RMSEA $=.075$, SRMR $=.044$, CFI $=.946$ for the Germanspeaking sample). Evidence of the construct validity of the scale can be inferred from the first study of the German-speaking sample [12]. The COVID stress scale showed a correlation of .5 with general mental distress, as measured with the sum score of the PHQ-4. This correlation is substantial enough to indicate the assumed shared variance, and small enough to suggest that two different constructs are being measured here. Furthermore, the COVID-19 stress scale showed correlations with psychological measures that corresponded to published relationships between those and other stress measures [46]: Meaningfulness (-.28), crisis of meaning (.41), and self-control (-.21). As reported for the established Coronavirus Anxiety Scale (CAS) [14], also our COVID-19 scale showed a small negative correlation with age $(.21, p<.001)$.

General mental distress We measured mental distress with the Patient Health Questionnaire 4, PHQ-4, [47, 48], a brief four-item measure of core symptoms of depression and anxiety. It uses a four-point Likert scale ranging from 0 (not at all) to 3 (nearly every day). Participants were asked to respond to the items with a view to the past two weeks. Studies from the last decade reported Cronbach alpha values between .78 and .85 and established construct validity and factorial validity of the PHQ-4 [47, 49-51]. Several findings have confirmed its validity as a measure of general mental distress, with correlations of around .70 with established indicators of general mental distress (e.g. [47, 50-52]). A recent study found that the PHQ-4 sum score and the sum score of the PHQ-ADS, a 16-item combination of the PHQ-9 and GAD-7, correlated comparably strong with other indicators of general mental distress [51]. The PHQ-4 has also demonstrated good reliability and validity in clinical and population samples for the Norwegian and German versions (e.g. [47-50, 53, 54]). McDonald's omegas in this study were .91 (Norwegian sample), and .91 (German-speaking sample). Several cut-off points have been validated with $>2,>3,>5$ indicating mild, moderate, and severe mental distress $[47,50]$.

Demographics and living conditions The sociodemographic section assessed participants' age, gender, relationship status, children, living together status, education, and personal experiences with Sars-CoV-2 infections. The specific categories of the demographic variables are shown in Table 1.

\section{Statistical analyses}

Descriptive results are expressed as relative frequencies in percent, as well as means and standard deviations. Comparisons of the two samples were performed using chi-square tests for categorical data and t-tests for continuous data. The reliability coefficient McDonald's omega was calculated with IBM SPSS AMOS 25 Graphics, as described by Hayes \& Coutts [55]. For all statistical tests, a two-tailed $p$-value $\leq .05$ was considered statistically significant. Due to their small number, data from participants identifying as gender divers were excluded from analyses that contained gender as a variable.

Moderation analyses were conducted using the PROCESS macro, version 3.5 [56, 57] for SPSS, version 25 [58]. Multiple linear regression models tested whether the independent variables COVID-19 stress, internal LoC, external LoC, and the interaction between COVID-19 stress and internal and external LoC, respectively, had statistically significant associations with general mental distress as measured by the total score of the PHQ-4. In a further step, these moderation analyses were repeated including the covariates age, gender, relationship status, children, living together status, and education.

The statistical interaction between the independent variables 'COVID-19 stress' on the one hand and 'internal LoC' and 'external LoC' on the other hand indicated whether individual differences in LoC moderated individual differences of severity of mental distress in participants with varying severity of acute COVID-19 stress. In order to probe the interactions, analyses using the Johnson-Neyman technique were conducted for all eight regression models (four regression analyses by two samples) [57]. The Johnson-Neyman technique calculates the statistical significance of the effect of an independent variable, in this study COVID-19 stress, for all values of the moderator variable, in this study internal or external LoC. Thus, the Johnson-Neyman technique can 'identify points of transition along the continuum of the moderator between a statistically significant and nonsignificant effect of $X^{\prime}$ [57, page 13]. The resulting ranges of the values of the moderator where the independent variable is significantly associated with the dependent variable are called regions of significance.

\section{Results}

\section{Sample characteristics and zero-order correlations}

The two study samples differed significantly concerning demographic and psychological characteristics (Table 1). Compared with the German-speaking sample $(n=1527)$, the Norwegian sample $(n=1225)$ was older and had higher percentages of women, of people with children, and of people with university education. The Norwegian 
sample had lower scores of both internal and external LoC, lower COVID-19 stress, as well as lower general mental distress, depression, and anxiety. Correspondingly, compared with the German-speaking participants, the Norwegian sample had lower rates of clinically significant depression (14.3\% versus $22.7 \%$ ), anxiety (10.0\% versus $21.0 \%)$, and severe general mental distress $(9.1 \%$ versus $19.1 \%$ ). While there were small but statistically significant differences in relationship status and Sars CoV-2 infection rates of close persons, the samples did not differ regarding living together status and personal Sars CoV-2 infection rates.

Table 2 displays the intercorrelations between COVID-19 stress, general mental distress, LoC I, and LoC E. In both samples, COVID-19 stress and general mental distress had large positive correlations. All other correlations were of moderate to small size, with LoC I and LoC E correlating negatively with each other, and COVID-19 stress and general mental distress correlating negatively with LoC I, and positively with LoC E. The psychological variables were only weakly associated with demographic characteristics, however the majority of these correlations reached statistical significance in both samples (Table 3), suggesting to include the demographic variables into adjusted moderation analyses of the psychological variables. No significant correlations were found between psychological variables and experiences with Sars CoV-2 infections.

\section{Moderation analyses}

Table 4 shows the results of multiple regression models analysing the prediction of general mental distress (PHQ-4 sum score). COVID-19 stress, LoC I, LoC E, and the interaction between COVID-19 stress and LoC I and LoC E, respectively, had statistically significant independent effects on general mental distress in both the

Table 2 Correlations between locus of control (LoC), COVID-19 stress, and general mental distress

\begin{tabular}{|c|c|c|c|}
\hline & LoC I ${ }^{\text {a) }}$ & LoC $^{\text {a) }}$ & COVID-19 stress $^{b)}$ \\
\hline \multicolumn{4}{|l|}{ a. Norwegian sample $(n=1225)$} \\
\hline LOC E & $-.22^{* * *}$ & & \\
\hline COVID-19 stress & $-.11^{* * *}$ & $.32^{* * *}$ & \\
\hline General mental distress ${ }^{c)}$ & $-.14^{* * *}$ & $.32^{* * *}$ & $.61^{* * *}$ \\
\hline \multicolumn{4}{|c|}{ b. German-speaking sample ( $n=1527)$} \\
\hline LoC E & $-.41^{* * *}$ & & \\
\hline COVID-19 stress & $-.15^{* * *}$ & $.25^{* * *}$ & \\
\hline General mental distress $^{c)}$ & $-.31^{* * *}$ & $.35^{* * *}$ & $.55^{* * *}$ \\
\hline \multicolumn{4}{|c|}{$\begin{array}{l}\text { *** } \mathrm{p}<.001 \\
\text { a) LoC measured by the IE-4 subscales LoC Internal and LoC External } \\
\text { (range: } 1-5 \text { ) } \\
\text { b) Acute psychological stress due to COVID-19 measured by the COVID-19 } \\
\text { stress scale (range: } 0-5 \text { ) } \\
\text { c) General mental distress measured by the PHO-4 (range } 0-12 \text { ) }\end{array}$} \\
\hline
\end{tabular}

Norwegian and German-speaking samples. Higher COVID-19 stress, lower LoC I, and higher LoC E predicted higher general mental distress. The significant interactions indicated moderation effects. While higher LoC I buffered the effect of COVID-19 stress on general mental distress, higher LoC E exacerbated the effect. Figures $1 \mathrm{a}$ and $\mathrm{b}$ display plots of Johnson-Newman analyses to illustrate the interactions of COVID-19 stress and LoC I and LoC E, respectively. With increasing scores of LoC I, the conditional effect of COVID-19 stress on general mental distress decreased. With rising scores of LoC $\mathrm{E}$, it increased. The conditional effects were significant for the total range of scores of LoC I and LoC E. Finally, Table 4 shows that all associations between the psychological variables and general mental distress remained significant when the moderation analyses were adjusted for the demographic variables age, gender, relationship status, having children, living together status, and education.

\section{Discussion \\ Major findings}

This study investigated whether internal LoC and external LoC moderated the relationship between COVID-19 stress and general mental distress during the early months of the COVID-19 pandemic. Our major finding is that both aspects of LoC showed substantial moderation effects that proved to be robust in two different samples. In both the Norwegian and the Germanspeaking sample, LoC I served as a buffer of stress, while LoC E exacerbated stress. These results were found in unadjusted regression models and persisted in adjusted regression analyses. The association between COVID-19 stress and general mental distress was strong and pervasive, as indicated by significant conditional effects for the total range of scores of LoC I and LoC E. However, it was attenuated by the belief that the outcome of events in one's life are contingent upon one's actions (LoC I). On the contrary, the belief that chance and powerful others control one's life (LoC E) even increased the already strong association between COVID-19 stress and mental distress. This suggests that the pandemic is particularly difficult to bear for those people who, in addition to any pandemic-related strains that may arise, feel that they have little influence on their own lives in general. The quasi-invisible and difficult to comprehend threat of a virus as well as restrictions on one's own life determined by "powerful others" seem to reinforce a prevailing lack of self-control, as suggested by the positive correlation between COVID-19 stress and LoC E, and its negative correlation with LoC I. This was accompanied by drastically poorer mental health.

The opposite effect, which was found with a high internal locus of control, suggests that this is an important 
Table 3 Correlations between demographic variables and LOC, COVID-19 stress, and general mental distress

\begin{tabular}{|c|c|c|c|c|}
\hline & LoC I ${ }^{h)}$ & LoC $E^{\text {h) }}$ & COVID-19 stress i) & General mental distress $^{k}$ \\
\hline \multicolumn{5}{|l|}{ a. Norwegian sample $(n=1209$-1225) } \\
\hline Age (years) & -.06 & $-.10^{* *}$ & $-.12^{* * *}$ & $-.19^{* * *}$ \\
\hline Gender ${ }^{\text {a) }}$ & .03 & $-.06^{*}$ & .03 & .05 \\
\hline Relationship status ${ }^{\text {b) }}$ & $-.13^{* * *}$ & -.01 & $-.11^{* * *}$ & $-.12^{* * *}$ \\
\hline (hildren c) & -.03 & -.06 & $-.15^{* * *}$ & $-.19^{* * *}$ \\
\hline Living together status ${ }^{\text {d) }}$ & -.05 & .04 & $-.10^{* * *}$ & $-.10^{* * *}$ \\
\hline Education ${ }^{e)}$ & -.02 & $-.07^{*}$ & $-.08^{* *}$ & $-.11^{* * *}$ \\
\hline Infected Sars CoV-2 ${ }^{f)}$ & -.04 & -.02 & -.02 & -.01 \\
\hline Close person infected with Sars CoV-2 g) & -.02 & -.002 & .02 & -.02 \\
\hline \multicolumn{5}{|l|}{ b. German-speaking sample ( $n=1521-1527)$} \\
\hline & LoC I h) & LOC $E^{h)}$ & COVID-19 stress i) & General mental distress ${ }^{\mathrm{k})}$ \\
\hline Age (years) & $-.20^{* * *}$ & $.09^{* *}$ & $-.21^{* * * *}$ & $-.17^{* * *}$ \\
\hline Gender a) & $.06^{*}$ & .00 & $.11^{* * *}$ & $.06^{*}$ \\
\hline Relationship status b) & $-.09^{* *}$ & $-.07^{* *}$ & $-.13^{* * *}$ & $-.12^{* * *}$ \\
\hline (hildren ${ }^{c)}$ & $-.10^{* * *}$ & $.09^{* * *}$ & $-.14^{* * *}$ & $-.14^{* * *}$ \\
\hline Living together status ${ }^{\text {d) }}$ & $.15^{* * *}$ & -.01 & $-.05^{*}$ & $-.06^{*}$ \\
\hline Education ${ }^{\text {e) }}$ & -.02 & $-.11^{* * *}$ & $-.08^{* *}$ & $-.10^{* * *}$ \\
\hline Infected Sars CoV-2 ${ }^{f)}$ & .03 & -.03 & -.01 & -.02 \\
\hline Close person infected with Sars CoV-2 ${ }^{\text {g) }}$ & .04 & -.01 & -.004 & -.03 \\
\hline
\end{tabular}

${ }^{*} p<.05,{ }^{* *} p<.01,{ }^{* * *} \mathrm{p}<.001$

a) $1=$ male, $2=$ female

b) $0=$ not partnered; $1=$ married/partnered

c) $0=$ no children, $1=$ children

d) $0=$ living alone, 1 = living with somebody

e) $0=$ secondary/advanced, $1=$ university

f) $0=$ not infected with Sars CoV-2/ do not know, $1=$ infected with Sars CoV-2

g) $0=$ close person not infected with Sars CoV-2/ do not know, $1=$ close person infected with Sars CoV-2

h) LoC measured by the IE-4 subscales LoC Internal and LoC External (range: 1-5)

i) Acute psychological stress due to COVID-19 measured by the COVID-19 stress scale (range: $0-5$ )

k) General mental distress measured by the PHQ-4 (range 0-12)

resource that should be focused on with regard to public health measures. The actions of political decisionmakers can positively or negatively influence citizens' experience of control, depending on the degree of involvement of representatives of different interest groups in decision-making processes [59]. Similarly, the form of policy communication is likely to have an impact on whether citizens perceive themselves as empowered or patronized, as has been evidenced in relation to young adults' conflict strategies with superiors [60]. Last but not least, there are indications that a sense of control is associated with health behaviour and better health literacy $[61,62]$ - an aspect which, in the context of a pandemic, should not be separated from mental health.

Our results are consistent with the studies by Sigurvinsdottir et al. (2020) [40] and Alat et al. (2021) [41] who found moderate associations of higher external LoC and lower internal LoC, respectively, with mental distress during the COVID-19 pandemic. In the investigation by Berg \& Lin (2020), COVID-19 preventative behaviors were not related to internal health-related
LoC, but to external health-related LoC regarding powerful others [39]. It is beyond the scope of this article to discuss details of these counterintuitive results. However, it is important to keep in mind that the established mental health promoting effects of a high internal LoC and a low external LoC do not necessarily imply that these resources also promote preventive behavior that is based on self-restrictions and discipline. In terms of the current state of research, it can be said that, to our knowledge, until now the moderating role of LoC has not been investigated with respect to COVID-19 related outcomes. Our findings add to and confirm results of previous studies that established $\mathrm{LoC}$ as a factor that can maintain and improve (LoC I) or jeopardize (LoC E) mental health under stressful conditions [30, 34-38, 40, 41]. It can be assumed that locus of control and stress management interact in different ways. Early on, Rotter (1966) posited that the respective locus of control has an impact on how stress is perceived [29]. Individuals with an internal locus of control should be more likely to see difficult tasks as challenges rather than as something to 
Table 4 Simple moderation: LoC moderates COVID-19 stress predicting general mental distress

a. Unadjusted moderation Norwegian sample $(n=1225)$

Regression analysis 1: Internal locus of control (LoC I)

Intercept
COVID-19 stress (IV)
LOCI (Mod)

Coeff (SE) $[95 \% \mathrm{CI}]$

COVID-19 stress $\times$ LoC I

$1.72(0.07)[1.59 ; 1.85]$

$-0.21(0.06)[-0.33 ;-0.09]$

$-0.22(0.07)[-0.35 ;-0.09]$ $t$

46.93

26.31

$-3.40$

$-3.23$

Regression analysis 2: External locus of control (LoC E)

Intercept
COVID-19 stress (IV)
LoC E (Mod)

COVID-19 stress $x$ LOC E

\section{b. Adjusted moderation}

Coeff (SE) $[95 \% \mathrm{Cl}]$
$2.44(0.05)[2.33 ; 2.54]$
$1.58(0.07)[1.45 ; 1.71]$
$0.39(0.07)[0.25 ; 0.54]$
$0.35(0.08)[0.20 ; 0.50]$
Norwegian sample $(n=1205)$

Regression analysis 1: Internal locus of control (LoC I)

\begin{tabular}{|c|c|}
\hline & Coeff (SE) [95\% CI] \\
\hline Intercept & $3.84(0.36)[3.14 ; 4.55]$ \\
\hline COVID-19 stress (IV) & $1.63(0.07)[1.50 ; 1.76]$ \\
\hline LoC I (Mod) & $-0.26(0.06)[-0.38 ;-0.14]$ \\
\hline COVID-19 stress $\times$ LoC I & $-0.20(0.07)[-0.33 ;-0.06]$ \\
\hline Age (years) & $-0.02(0.01)[-0.03 ;-0.01]$ \\
\hline Gender a) & $0.21(0.12)[-0.03 ; 0.44]$ \\
\hline Relationship status ${ }^{\text {b) }}$ & $0.01(0.13)[-0.25 ; 0.26]$ \\
\hline Children ${ }^{c)}$ & $-0.22(0.16)[-0.53 ; 0.09]$ \\
\hline Living together status ${ }^{d)}$ & $-0.26(0.16)[-0.58 ; 0.06]$ \\
\hline Education e) & $-0.45(0.16)[-0.77 ;-0.14]$ \\
\hline
\end{tabular}

Regression analysis 2: External locus of control (LoC E)

\begin{tabular}{|c|c|c|c|c|c|c|}
\hline & Coeff (SE) $[95 \%$ Cl] & t & $p$ & Coeff (SE) $[95 \%$ Cl] & $t$ & $p$ \\
\hline Intercept & $3.65(0.36)[2.95 ; 4.34]$ & 10.28 & $<.001$ & $4.23(0.34)[3.56 ; 4.90]$ & 12.44 & $<.001$ \\
\hline COVID-19 stress (IV) & $1.50(0.07)[1.37 ; 1.64]$ & 21.81 & $<.001$ & $1.46(0.07)[1.32 ; 1.59]$ & 20.82 & $<.001$ \\
\hline LoC E (Mod) & $0.39(0.07)[0.25 ; 0.54]$ & 5.31 & $<.001$ & $0.75(0.07)[0.61 ; 0.89]$ & 10.51 & $<.001$ \\
\hline COVID-19 stress $\times$ LoC E & $0.37(0.08)[0.22 ; 0.51]$ & 4.88 & $<.001$ & $0.28(0.07)[0.15 ; 0.42]$ & 3.99 & $<.001$ \\
\hline Age (years) & $-0.02(0.01)[-0.03 ;-0.01]$ & -3.73 & $<.001$ & $-0.01(0.01)[-0.02 ; 0.001]$ & -1.83 & .067 \\
\hline Gender ${ }^{\text {a) }}$ & $0.24(0.12)[0.01 ; 0.47]$ & 2.01 & .045 & $-0.02(0.13)[-0.27 ; 0.22]$ & -0.18 & .855 \\
\hline Relationship status b) & $0.02(0.13)[-0.23 ; 0.27]$ & 0.16 & .870 & $0.05(0.14)[-0.22 ; 0.33]$ & 0.38 & .706 \\
\hline (hildren ${ }^{c)}$ & $-0.22(0.16)[-0.53 ; 0.08]$ & -1.44 & .151 & $-0.37(0.16)[-0.69 ;-0.05]$ & -2.30 & .022 \\
\hline Living together status ${ }^{d)}$ & $-0.30(0.16)[-0.61 ; 0.02]$ & -1.86 & .063 & $-0.24(0.17)[-0.57 ; 0.09]$ & -1.43 & .153 \\
\hline Education e) & $-0.41(0.16)[-0.72 ;-0.10]$ & -2.60 & .009 & $-0.18(0.12)[-0.42 ; 0.05]$ & -1.55 & .123 \\
\hline
\end{tabular}

German-speaking sample $(n=1527)$

$\begin{array}{lll}\text { Coeff (SE) }[95 \% \mathrm{CI}] & t & p \\ 3.46(0.06)[3.35 ; 3.57] & 59.45 & <.001 \\ 1.63(0.07)[1.50 ; 1.76] & 24.66 & <.001 \\ -0.75(0.07)[-0.89 ;-0.61] & -10.32 & <.001 \\ -0.23(0.07)[-0.36 ;-0.10] & -3.39 & <.001 \\ & & \\ \text { Coeff (SE) }[95 \% \mathrm{CI}] & t & p \\ 3.43(0.06)[3.32 ; 3.55] & 57.87 & <.001 \\ 1.55(0.07)[1.42 ; 1.68] & 22.99 & <.001 \\ 0.71(0.07)[0.57 ; 0.84] & 10.05 & <.001 \\ 0.27(0.07)[0.13 ; 0.41] & 3.83 & <.001\end{array}$

\begin{tabular}{|c|c|c|c|c|}
\hline$t$ & $p$ & Coeff (SE) $[95 \%$ CI] & $t$ & $p$ \\
\hline 10.69 & $<.001$ & $4.24(0.34)[3.57 ; 4.90]$ & 12.51 & $<.001$ \\
\hline 24.66 & $<.001$ & $1.52(0.07)[1.39 ; 1.66]$ & 22.32 & $<.001$ \\
\hline-4.30 & $<.001$ & $-0.84(0.08)[-0.99 ;-0.70]$ & -11.21 & $<.001$ \\
\hline-2.91 & .004 & $-0.23(0.07)[-0.36 ;-0.10]$ & -3.44 & $<.001$ \\
\hline-4.04 & $<.001$ & $-0.01(0.01)[-0.02 ;-0.00]$ & -2.55 & .011 \\
\hline 1.75 & .080 & $0.00(0.12)[-0.24 ; 0.25]$ & 0.03 & .979 \\
\hline 0.04 & .969 & $0.06(0.14)[-0.22 ; 0.33]$ & 0.40 & 689 \\
\hline-1.39 & .166 & $-0.31(0.16)[-0.62 ; 0.01]$ & -1.88 & .060 \\
\hline-1.62 & .105 & $-0.00(0.17)[-0.33 ; 0.33]$ & -0.02 & .983 \\
\hline-2.82 & .005 & $-0.33(0.12)[-0.57 ;-0.10]$ & -2.81 & .005 \\
\hline$t$ & $p$ & Coeff (SE) $[95 \%$ CI] & $t$ & $p$ \\
\hline 10.28 & $<.001$ & $4.23(0.34)[3.56 ; 4.90]$ & 12.44 & $<.001$ \\
\hline 21.81 & $<.001$ & $1.46(0.07)[1.32 ; 1.59]$ & 20.82 & $<.001$ \\
\hline 5.31 & $<.001$ & $0.75(0.07)[0.61 ; 0.89]$ & 10.51 & $<.001$ \\
\hline 4.88 & $<.001$ & $0.28(0.07)[0.15 ; 0.42]$ & 3.99 & $<.001$ \\
\hline-3.73 & $<.001$ & $-0.01(0.01)[-0.02 ; 0.001]$ & -1.83 & .067 \\
\hline 2.01 & .045 & $-0.02(0.13)[-0.27 ; 0.22]$ & -0.18 & .855 \\
\hline 0.16 & .870 & $0.05(0.14)[-0.22 ; 0.33]$ & 0.38 & .706 \\
\hline-1.44 & .151 & $-0.37(0.16)[-0.69 ;-0.05]$ & -2.30 & .022 \\
\hline-1.86 & .063 & $-0.24(0.17)[-0.57 ; 0.09]$ & -1.43 & .153 \\
\hline-2.60 & .009 & $-0.18(0.12)[-0.42 ; 0.05]$ & -1.55 & .123 \\
\hline
\end{tabular}

$0=$ secondary/advanced, $1=$ university

be avoided. They should thus be more hopeful, active, and more likely to take responsibility for themselves and their environment. Correspondingly, LoC has been linked to different coping strategies [63]. A recent metaanalysis showed that internal LoC is indeed associated with adaptive coping (problem-focused and active strategies), and maladaptive LoC (excessive external locus and a lack of internal locus of control) with maladaptive coping, including avoidant and emotion-oriented strategies [37]. 


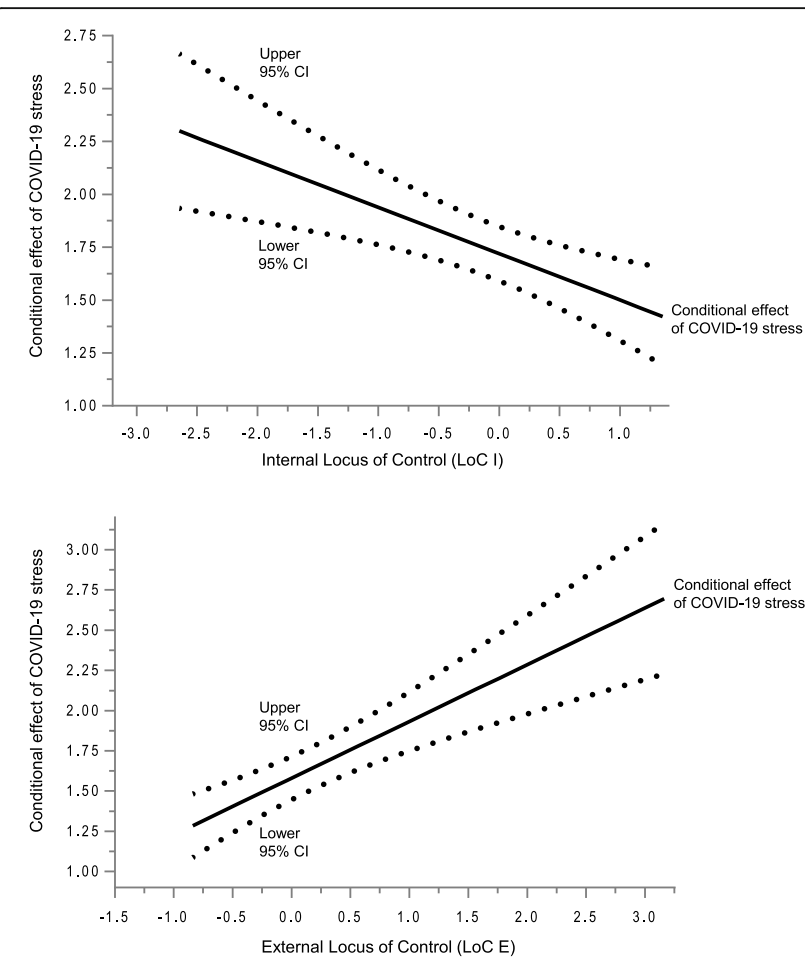

a.Norwegian sample $(n=1225)$
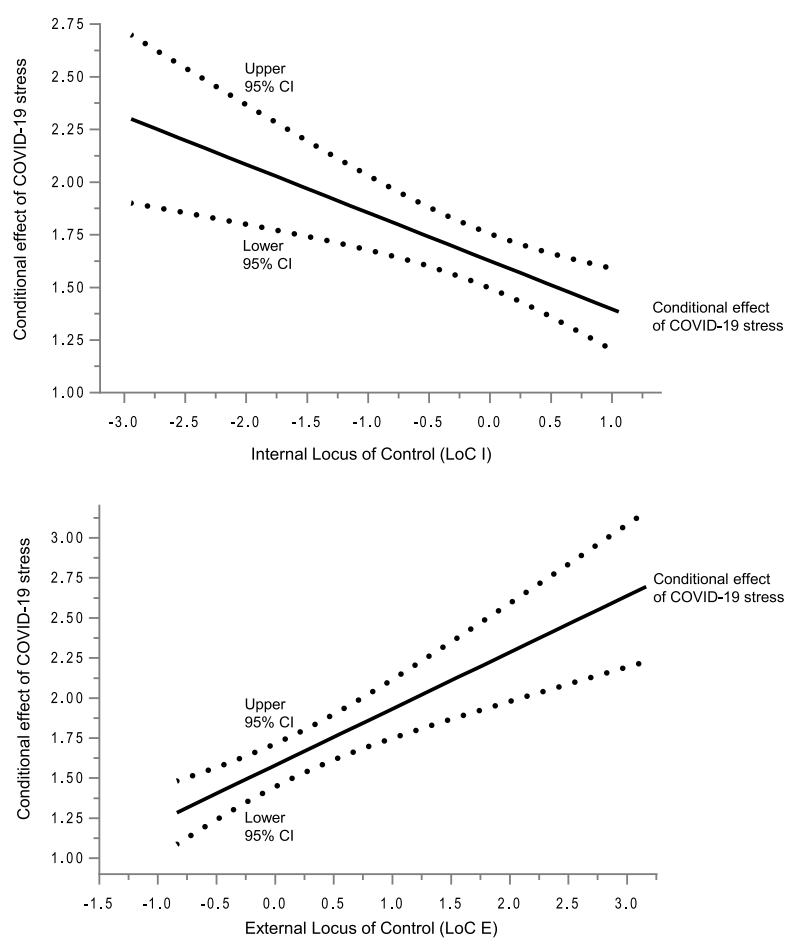

b.German-speaking sample $(n=1527)$

Fig. 1 a, b. Johnson-Neyman plots of the interaction between COVID-19 stress and LoC. Moderators: LoC I (upper graphs), LoC E (lower graphs). The black continuous lines show the conditional effects of COVID-19 stress on general mental distress (PHQ-4) for all values of LoC, and the dotted lines above and below indicate the corresponding 95\% confidence intervals (Cl)

The study samples in the context of COVID-19 mental distress research

Both study samples showed consistent major results, although they differed in their contextual background including pandemic stage, and demographic and psychological characteristics. On average, the Norwegian participants were older, better educated, more likely to be female and to have children. They also had better mental health, as indicated by less COVID-19 stress and lower rates of clinically significant general mental distress, also evidenced separately for depression and anxiety. An inspection of sample characteristics of recent psychological studies on pandemic-related moderator factors suggests that in the majority of these, participants were mostly young adults, more likely to be well-educated, and female [18-27]. Samples with high percentages of young adults and women also characterize epidemiological research on mental distress during the pandemic $[2,3,6,8]$ and the majority of studies of measurement of COVID-19 stress [11]. While both of our samples are comparable with these study characteristics concerning education and gender, the inclusion of middle-aged and older adults counterbalances the overrepresentation of younger adults in psychological COVID-19 research and offers a better generalisability over different age groups.
Concerning mental health, findings are available from recent systematic reviews and meta-analyses of mental distress in the general population at the beginning of the COVID-19 pandemic [1-8]. Compared with these synthesized prevalence data, the frequencies of clinically relevant depression, anxiety, and general mental distress in the German-speaking sample are in the middle range, and in the lower range in the Norwegian sample. Similar results were found in a study comparing mental health during the onset of the pandemic in Norway, Germany, and four other countries [43]. Prevalence of mental distress was higher in another Norwegian large-scale investigation that was carried out when all COVID-19 regulations were in force, and that was based on a sample with predominantly young adults [64]. Still, both the Norwegian and German-speaking samples presented here revealed degrees of mental distress that are higher than those reported in general population samples before the COVID-19 pandemic [49, 65-67].

\section{Elevated mental distress during the COVID-19 pandemic}

There is ample evidence that mental disorders contribute to individual impairment and disability, as well as global burden of disease [68]. It is thus highly important to prevent COVID-19 stress and elevated mental distress from turning into pathology and mental disorders. On 
the other hand, elevated COVID-19 stress, and even temporarily increased symptoms of depression and anxiety can be regarded as functional psychological responses to a worldwide outbreak of a novel and lifethreatening virus disease. Findings of strong stress reactions to a threatening situation should therefore not be "awfulized" by lurid headlines, which risks further exacerbating pathological developments (see [69]). We should also consider that data are still lacking on the long-term course of mental health after the COVID-19 pandemic. Preliminary follow-up data of the Germanspeaking sample suggest that mental distress increased directly after the first lockdown in spring 2020, and decreased slightly three months later, when the number of confirmed Sars-CoV-2 infections per million people in Europe was rather low [12, 70]. A recent large-scale study investigated differential trajectories of mental distress over eight weeks of full lockdown and subsequent eight weeks of easing of lockdown [71]. The authors found that previous mental health diagnoses, long-term health conditions, younger age, and lower incomes were among the strongest predictors of worse trajectories. While there are findings of significantly elevated mental distress even months and years after previous viral respiratory epidemics [72-74], these do not refer to the general population but to people who had personally experienced traumatic events, either as health care workers or as survivors of critical disease due to the respective respiratory syndromes.

\section{Limitations and strengths}

The present study is based on two large samples from the general population which are, however, not representative. We accounted for this limitation by including important sociodemographic covariates in the analyses. Unadjusted as well as adjusted regression analyses yielded consistent results in both samples.

The 4-item Internal/External Locus of Control-4 Scale (IE-4) is a short scale, and questions may arise concerning its psychometric properties. In both samples of the present study, the two subscales showed McDonald's omegas that were comparable with the omega values of the normative samples of the IE-4, suggesting sufficient reliability. For the German version, convincing data are reported regarding content, factorial, and construct validity [32]. The robust results of the current analyses also suggest sufficient validity of the IE-4.

It should be emphasised once again that our main outcome measure, the PHQ-4, does not establish diagnoses of mood or anxiety disorders according to ICD-10 or DSM-5. It measures core symptoms of both, thus indicating, by means of several cut-off scores, occurrence of clinically relevant symptoms. The PHQ-4 has been demonstrated to be a valid screening tool for general mental distress in the general population and clinical populations [e.g., 47-54, 66].

The COVID-19 stress scale was newly developed for the current investigation, as no instruments were available at the time we initiated the project [12]. In both samples of the present study, reliabilities were good, and results of confirmatory factor analyses suggest a onedimensional model of COVID-19 stress. Its relationships with LoC, as well as with meaning in life, self-control, and crisis of meaning [12] corresponded to our hypotheses and can thus be considered as first evidence for construct validity.

\section{Conclusions}

Our findings can offer important insights into how people with certain personality characteristics are wellequipped, whereas others are particularly vulnerable in times of crisis. According to the present study, people with an external locus of control are at special risk.

Decision-makers in the field of public health can take this into account. Improving citizens' sense of control can help prevent increased mental distress from developing into mental disorders. Experiencing a sense of control may encourage citizens to adhere to necessary restrictions of individual freedom as a possible outcome of informed personal choice, rather than simply obeying an imposed rule. Possible ways of evoking a sense of control include clear, honest, and substantiated policy communication that is based on multiple perspectives, as well as explicit invitation of citizens to participate in decision-making, e.g. by expressing questions and objections. Although critical situations may require quick decisions and the short-term suspension of democratic processes, this should be done with utmost care, transparent explanation, and the quickest possible return to political action that seriously and credibly incorporates and implements citizens' concerns. Feelings of stress caused by the pandemic on the one hand and of one's own lack of control on the other hand obviously feed off each other, which is reflected in a worrying level of psychological distress.

\section{Supplementary Information}

The online version contains supplementary material available at https://doi. org/10.1186/s12888-021-03418-5.

Additional file 1:. Supplementary Table S1: COVID-19 Stress scale.

Acknowledgements

We wish to thank Tor-Arne Isene for his help in data management of the Norwegian sampling.

Authors' contributions

HK and TS wrote the manuscript and performed the statistical analyses. HK participated in the investigation of the German-speaking data. LJD and GS conceptualized, developed, and conducted the Norwegian survey; LD 
performed data curation and project administration of the Norwegian data set. AH contributed to the conceptualization and development of the Norwegian Survey. TS conceptualized and designed the overall study, conducted the investigation of the German-speaking data, and performed the data curation of both data sets. All authors discussed the results, commented on the paper, contributed to the critical revision of the manuscript, and read and approved the final manuscript.

\section{Funding}

The Norwegian part of the study was financed by Innlandet Hospital Trust, Norway. The German-speaking part was conducted in the absence of financial funding.

\section{Availability of data and materials}

The datasets used and/or analysed during the current study are available from the corresponding author on reasonable request.

\section{Declarations}

\section{Ethics approval and consent to participate}

Ethics approval was issued by the Review Board (Psychology) of the University of Innsbruck, No 09/2020, as well as by Personvernombudet Innlandet Hospital Trust, Norway, No 20/02104-1. All participants expressed their informed consent by explicitly agreeing to continue with the questionnaire after being informed about the study's aims, employed data protection, participants' rights, and contact points for questions or concerns. All methods were carried out in accordance with relevant guidelines and regulations.

\section{Consent for publication}

Not applicable.

\section{Competing interests}

The authors declare that they have no competing interests.

\section{Author details}

${ }^{1}$ Department of Anesthesiology and Operative Intensive Care Medicine (CCM, CVK), Charité - Universitätsmedizin, corporate member of Freie Universität Berlin, Humboldt-Universität zu Berlin, and Berlin Institute of Health, Berlin, Germany. ${ }^{2}$ Practical Theology, MF Norwegian School of Theology, Religion and Society, Oslo, Norway. ${ }^{3}$ Centre for Psychology of Religion, Innlandet Hospital Trust, Ottestad, Norway. ${ }^{4}$ Faculty of Social Sciences, Norwegian School of Hotel Management, University of Stavanger, Stavanger, Norway. ${ }^{5}$ Faculty of Social Sciences, School of Psychology, University of Wollongong, Wollongong, NSW, Australia. ${ }^{6}$ Social Sciences, MF Norwegian School of Theology, Religion and Society, Oslo, Norway. ${ }^{7}$ Modum Bad Psychiatric Center, Vikersund, Norway. ${ }^{8}$ Existential Psychology Lab, Institute of Psychology, University of Innsbruck, Innsbruck, Austria.

\section{Received: 30 April 2021 Accepted: 3 August 2021}

\section{Published online: 06 September 2021}

\section{References}

1. Arora T, Grey I, Östlundh L, Lam KBH, Omar OM, Arnone D. The prevalence of psychological consequences of COVID-19: a systematic review and metaanalysis of observational studies. J Health Psychol. 2020:1-20. https://doi. org/10.1177/1359105320966639.

2. Bareeqa SB, Ahmed SI, Samar SS, Yasin W, Zehra S, Monese GM, et al. Prevalence of depression, anxiety and stress in China during COVID-19 pandemic: a systematic review with meta-analysis. Int J Psychiatry Med. 2020;56(4):1-18. https://doi.org/10.1177/0091217420978005.

3. Bueno-Notivol J, Gracia-García P, Olaya B, Lasheras I, López-Antón R, Santabárbara J. Prevalence of depression during the COVID-19 outbreak: a meta-analysis of community-based studies. Int J Clin Health Psychol. 2021; 21(1):100196. https://doi.org/10.1016/j.ijchp.2020.07.007.

4. Luo M, Guo L, Yu M, Jiang W, Wang H. The psychological and mental impact of coronavirus disease 2019 (COVID-19) on medical staff and general public - a systematic review and meta-analysis. Psychiatry Res. 2020;291: 113190. https://doi.org/10.1016/j.psychres.2020.113190.

5. Salari N, Hosseinian-Far A, Jalali R, Vaisi-Raygani A, Rasoulpoor S, Mohammadi $\mathrm{M}$, et al. Prevalence of stress, anxiety, depression among the general population during the COVID-19 pandemic: a systematic review and meta-analysis. Glob Health. 2020;16(1):57. https://doi.org/10.1186/s12 992-020-00589-W.

6. Wang Y, Kala MP, Jafar TH. Factors associated with psychological distress during the coronavirus disease 2019 (COVID-19) pandemic on the predominantly general population: a systematic review and meta-analysis. PLoS One. 2021;15(12):e0244630. https://doi.org/10.1371/journal.pone.0244 630.

7. Wu T, Jia X, Shi H, Niu J, Yin X, Xie J, et al. Prevalence of mental health problems during the COVID-19 pandemic: a systematic review and metaanalysis. J Affect Disord. 2021;281:91-8. https://doi.org/10.1016/j.jad.202 0.11 .117$.

8. Xiong J, Lipsitz O, Nasri F, Lui LMW, Gill H, Phan L, et al. Impact of COVID-19 pandemic on mental health in the general population: a systematic review. J Affect Disord. 2020;277:55-64. https://doi.org/10.1016/j.jad.2020.08.001.

9. Asmundson GJG, Taylor S. Coronaphobia: fear and the 2019-nCoV outbreak. J Anxiety Disord. 2020;70:102196. https://doi.org/10.1016/j.janxdis.2020.1021 96.

10. Fiorillo A, Gorwood P. The consequences of the COVID-19 pandemic on mental health and implications for clinical practice. Eur Psychiatry. 2020; 63(1):e32. https://doi.org/10.1192/j.eurpsy.2020.35.

11. Ransing R, Ramalho R, Orsolini L, Adiukwu F, Gonzalez-Diaz JM, Larnaout A, et al. Can COVID-19 related mental health issues be measured? Brain Behav Immun. 2020;88:32-4. https://doi.org/10.1016/j.bbi.2020.05.049.

12. Schnell T, Krampe H. Meaning in life and self-control buffer stress in times of COVID-19: moderating and mediating effects with regard to mental distress. Front Psychiatry. 2020;11:582352. https://doi.org/10.3389/fpsyt.2020. 582352.

13. Ahorsu DK, Lin C-Y, Imani V, Saffari M, Griffiths MD, Pakpour AH. The fear of COVID-19 scale: development and initial validation. Int J Ment Heal Addict. 2020:1-9. https://doi.org/10.1007/s11469-020-00270-8.

14. Lee SA. Coronavirus anxiety scale: a brief mental health screener for COVID19 related anxiety. Death Stud. 2020;44(7):393-401. https://doi.org/10.1080/ 07481187.2020 .1748481 .

15. Sakib N, Bhuiyan AKMI, Hossain S, Al Mamun F, Hosen I, Abdullah AH, et al. Psychometric validation of the Bangla fear of COVID-19 scale: confirmatory factor analysis and Rasch analysis. Int J Ment Heal Addict. 2020. https://doi. org/10.1007/s11469-020-00289-X.

16. Satici B, Gocet-Tekin E, Deniz ME, Satici SA. Adaptation of the fear of COVID-19 scale: its association with psychological distress and life satisfaction in Turkey. Int J Ment Heal Addict. 2020. https://doi.org/10.1007/s11469-020-00294-0.

17. Taylor S, Landry CA, Paluszek MM, Fergus TA, McKay D, Asmundson GJG. Development and initial validation of the COVID stress scales. J Anxiety Disord. 2020;72:102232. https://doi.org/10.1016/j.janxdis.2020.102232.

18. Zhao X, Lan M, Li H, Yang J. Perceived stress and sleep quality among the non-diseased general public in China during the 2019 coronavirus disease: a moderated mediation model. Sleep Med. 2021;77:339-45. https://doi.org/1 0.1016/j.sleep.2020.05.021.

19. Smith BM, Twohy AJ, Smith GS. Psychological inflexibility and intolerance of uncertainty moderate the relationship between social isolation and mental health outcomes during COVID-19. J Contextual Behav Sci. 2020;18:162-74. https://doi.org/10.1016/j.jcbs.2020.09.005.

20. Prikhidko A, Long $H$, Wheaton MG. The effect of concerns about COVID-19 on anxiety, stress, parental burnout, and emotion regulation: the role of susceptibility to digital emotion contagion. Front Public Health. 2020;8: 567250. https://doi.org/10.3389/fpubh.2020.567250.

21. Knepple Carney A, Graf AS, Hudson G, Wilson E. Age moderates perceived COVID-19 disruption on well-being. The Gerontologist. 2021;61(1):30-5. https://doi.org/10.1093/geront/gnaa106.

22. Magson NR, Freeman JYA, Rapee RM, Richardson CE, Oar EL, Fardouly J. Risk and protective factors for prospective changes in adolescent mental health during the COVID-19 pandemic. J Youth Adolesc. 2021;50(1):44-57. https:// doi.org/10.1007/s10964-020-01332-9.

23. Yang Y, Liu K, Li S, Shu M. Social media activities, emotion regulation strategies, and their interactions on people's mental health in COVID-19 pandemic. Int J Environ Res Public Health. 2020;17(23). https://doi.org/10.33 90/ijerph17238931.

24. Du C, Zan MCH, Cho MJ, Fenton Jl, Hsiao PY, Hsiao R, et al. Increased resilience weakens the relationship between perceived stress and anxiety on sleep quality: a moderated mediation analysis of higher education 
students from 7 countries. Clocks Sleep. 2020;2(3):334-53. https://doi.org/1 0.3390/clockssleep2030025.

25. Harris SM, Sandal GM. COVID-19 and psychological distress in Norway: the role of trust in the healthcare system. Scand J Public Health. 2021:49(1):96103. https://doi.org/10.1177/1403494820971512.

26. Herbert JS, Mitchell A, Brentnall SJ, Bird AL. Identifying rewards over difficulties buffers the impact of time in COVID-19 lockdown for parents in Australia. Front Psychol. 2020;11(3441). https://doi.org/10.3389/fpsyg.2020. 606507

27. Yang X, Song B, Wu A, Mo PKH, Di J, Wang Q, et al. Social, cognitive, and eHealth mechanisms of COVID-19-related lockdown and mandatory quarantine that potentially affect the mental health of pregnant women in China: cross-sectional survey study. J Med Internet Res. 2021;23(1):e24495. https://doi.org/10.2196/24495.

28. Judge TA, Erez A, Bono JE, Thoresen CJ. Are measures of self-esteem, neuroticism, locus of control, and generalized self-efficacy indicators of a common core construct? J Pers Soc Psychol. 2002;83(3):693-710. https://doi. org/10.1037//0022-3514.83.3.693.

29. Rotter JB. Generalized expectancies for internal versus external control of reinforcement. Psychol Monogr. 1966;80(1):1-28. https://doi.org/10.1037/ h0092976.

30. Bjørkløf GH, Engedal K, Selbæk G, Maia DB, Borza T, Benth J, et al. Can depression in psychogeriatric inpatients at one year follow-up be explained by locus of control and coping strategies? Aging Ment Health. 2018;22(3): 379-88. https://doi.org/10.1080/13607863.2016.1262817.

31. Jakoby N, Jacob R. Messung von internen und externen Kontrollüberzeugungen in allgemeinen Bevölkerungsumfragen [Measurement of internal and external control convictions in general population surveys]. ZUMA Nachrichten. 1999;23(45):61-71 https://nbnresolving.org/urn:nbn:de:0168-ssoar-208124.

32. Kovaleva A, Beierlein C, Kemper C, Rammstedt B. Eine Kurzskala zur Messung von Kontrollüberzeugung: Die Skala Internale-ExternaleKontrollüberzeugung-4 (IE-4) [A short scale for the assessment of Locus of Control: The scale internal-external control - 4 (IE-4)]. GESIS-Working Papers 2012;2012|19.

33. Suárez-Álvarez J, Pedrosa I, García-Cueto E, Muñiz J. Locus of control revisited: development of a new bi-dimensional measure. Anales Psicol / Annals Psychol. 2016;32(2):578-86. https://doi.org/10.6018/analesps.32.2.2 00781.

34. Brown AJ, Thaker PH, Sun CC, Urbauer DL, Bruera E, Bodurka DC, et al. Nothing left to chance? The impact of locus of control on physical and mental quality of life in terminal cancer patients. Support Care Cancer. 2017; 25(6):1985-91. https://doi.org/10.1007/s00520-017-3605-z.

35. Cheng C, Cheung SF, Chio JH, Chan MP. Cultural meaning of perceived control: a meta-analysis of locus of control and psychological symptoms across 18 cultural regions. Psychol Bull. 2013;139(1):152-88. https://doi.org/1 $0.1037 / a 0028596$.

36. Gore JS, Griffin DP, McNierney D. Does internal or external locus of control have a stronger link to mental and physical health? Psychol Stud. 2016; 61(3):181-96. https://doi.org/10.1007/s12646-016-0361-y.

37. Groth N, Schnyder N, Kaess M, Markovic A, Rietschel L, Moser S, et al. Coping as a mediator between locus of control, competence beliefs, and mental health: a systematic review and structural equation modelling meta-analysis. Behav Res Ther. 2019;121:103442. https://doi.org/10.1016/j.brat.2019.103442.

38. Hovenkamp-Hermelink JHM, Jeronimus BF, van der Veen DC, Spinhoven $P$, Penninx B, Schoevers RA, et al. Differential associations of locus of control with anxiety, depression and life-events: a five-wave, nine-year study to test stability and change. J Affect Disord. 2019;253:26-34. https://doi.org/10.101 6/j.jad.2019.04.005.

39. Berg MB, Lin L. Prevalence and predictors of early COVID-19 behavioral intentions in the United States. Transl Behav Med. 2020;10(4):843-9. https:// doi.org/10.1093/tbm/ibaa085.

40. Sigurvinsdottir R, Thorisdottir IE, Gylfason HF. The impact of COVID-19 on mental health: the role of locus on control and internet use. Int J Environ Res Public Health. 2020;17(19):6985. https://doi.org/10.3390/ijerph17196985.

41. Alat P, Das SS, Arora A, Jha AK. Mental health during COVID-19 lockdown in India: role of psychological capital and internal locus of control. Curr Psychol. 2021. https://doi.org/10.1007/s12144-021-01516-x.

42. Oksanen A, Kaakinen M, Latikka R, Savolainen I, Savela N, Koivula A. Regulation and trust: 3-month follow-up study on COVID-19 mortality in 25
European countries. JMIR Public Health Surveill. 2020;6(2):e19218-e. https:// doi.org/10.2196/19218.

43. Mækelæ MJ, Reggev N, Dutra N, Tamayo RM, Silva-Sobrinho RA, Klevjer K, et al. Perceived efficacy of COVID-19 restrictions, reactions and their impact on mental health during the early phase of the outbreak in six countries. $\mathrm{S}$ Soc Open Sci. 2020;7(8):200644. https://doi.org/10.1098/rsos.200644.

44. Christensen T, Lægreid P. The coronavirus crisis—crisis communication, meaning-making, and reputation management. Int Public Manag J. 2020; 23(5):713-29. https://doi.org/10.1080/10967494.2020.1812455.

45. Johns Hopkins University. COVID-19 Data Repository by the Center for Systems Science and Engineering (CSSE) at Johns Hopkins University; https://github.com/CSSEGISandData/COVID-19. 2021.

46. Schnell T. The psychology of meaning in life. New York, Abingdon: Routledge; 2021.

47. Kroenke K, Spitzer RL, Williams JB, Monahan PO, Loewe B. An ultra-brief screening scale for anxiety and depression: the PHQ-4. Psychosomatics. 2009:50(6):613-21. https://doi.org/10.1176/appi.psy.50.6.613.

48. Kroenke K, Spitzer RL, Williams JB, Loewe B. The patient health questionnaire somatic, anxiety, and depressive symptom scales: a systematic review. Gen Hosp Psychiatry. 2010;32(4):345-59. https://doi.org/10.1016/j. genhosppsych.2010.03.006

49. Loewe B, Wahl I, Rose M, Spitzer C, Glaesmer H, Wingenfeld K, et al. A 4item measure for depression and anxiety: validation and standardization of the patient health Questionnaire-4 (PHQ-4) in the general population. J Affect Disord. 2010;122(1-2):86-95. https://doi.org/10.1016/.j.jad.2009.06.019.

50. Kerper L, Spies C, Tillinger J, Wegscheider K, Salz A-L, Weiß-Gerlach E, et al. Screening for depression, anxiety and general psychological distress in preoperative surgical patients: a psychometric analysis of the patient health questionnaire 4 (PHQ-4). Clinical Health Promotion. 2014;4(1):5-14.

51. Kroenke K, Baye F, Lourens SG. Comparative validity and responsiveness of PHQ-ADS and other composite anxiety-depression measures. J Affect Disord. 2019;246:437-43. https://doi.org/10.1016/j.jad.2018.12.098.

52. Glaesmer H, Braehler E, Grande G, Hinz A, Petermann F, Romppel M. The German version of the Hopkins symptoms Checklist-25 (HSCL-25) -factorial structure, psychometric properties, and population-based norms. Compr Psychiatry. 2014; 55(2):396-403. https://doi.org/10.1016/j.comppsych.2013.08.020.

53. Andreassen T, Hansen BT, Engesaeter B, Hashim D, Støer NC, Tropé A, et al. Psychological effect of cervical cancer screening when changing primary screening method from cytology to high-risk human papilloma virus testing. Int J Cancer. 2019;145(1):29-39. https://doi.org/10.1002/ijc.32067.

54. Solem S, Pedersen H, Nesse F, Garvik Janssen A, Ottesen Kennair LE, Hagen $R$, et al. Validity of a Norwegian version of the desire thinking questionnaire (DTQ): associations with problem drinking, nicotine dependence and problematic social media use. Clin Psychol Psychother. 2020;28(3):615-22. https://doi.org/10.1002/cpp.2524.

55. Hayes AF, Coutts JJ. Use Omega rather than Cronbach's Alpha for estimating reliability. But... Commun Methods Meas. 2020;14(1):1-24. https://doi.org/10.1080/19312458.2020.1718629.

56. Hayes AF. Introduction to mediation, moderation, and conditional process analysis: a regression-based approach. New York: Guilford Press; 2013.

57. Hayes AF, Rockwood NJ. Regression-based statistical mediation and moderation analysis in clinical research: Observations, recommendations, and implementation. Behav Res Ther. 2016;epub ahead of print. https://doi. org/10.1016/j.brat.2016.11.001.

58. IBM Corp. Released 2017. IBM SPSS statistics for windows, version 25.0. Armonk: IBM Corp; 2017.

59. Zimmerman MA, Rappaport J. Citizen participation, perceived control, and psychological empowerment. Am J Community Psychol. 1988;16(5):725-50. https://doi.org/10.1007/bf00930023.

60. Taylor M. Does locus of control predict young adult conflict strategies with superiors? An examination of control orientation and the organizational communication conflict instrument. N Am J Psychol. 2010;12(3):445-58.

61. Koelen MA, Lindström B. Making healthy choices easy choices: the role of empowerment. Eur J Clin Nutr. 2005;59 Suppl 1(S1):S10-S6. https://doi.org/1 0.1038/sj.ejcn.1602168.

62. Náfrádi L, Nakamoto K, Schulz PJ. Is patient empowerment the key to promote adherence? A systematic review of the relationship between selfefficacy, health locus of control and medication adherence. PLoS One. 2017; 12(10):e0186458. https://doi.org/10.1371/journal.pone.0186458. 
63. Follette VM, Jacobson NS. Importance of attributions as a predictor of how people cope with failure. J Pers Soc Psychol. 1987;52(6):1205-11. https://doi. org/10.1037//0022-3514.52.6.1205

64. Ebrahimi OV, Hoffart A, Johnson SU. Physical distancing and mental health during the COVID-19 pandemic: factors associated with psychological symptoms and adherence to pandemic mitigation strategies. Clin Psychol Sci. 2021;2167702621994545(3):489-506. https://doi.org/10.1177/2167702621 994545.

65. Dahl AA, Grotmol KS, Hjermstad MJ, Kiserud CE, Loge JH. Norwegian reference data on the fatigue questionnaire and the patient health Questionnaire-9 and their interrelationship. Ann General Psychiatry. 2020; 19(1):60. https://doi.org/10.1186/s12991-020-00311-5.

66. Schlax J, Wiltink J, Beutel ME, Münzel T, Pfeiffer N, Wild P, et al. Symptoms of depersonalization/derealization are independent risk factors for the development or persistence of psychological distress in the general population: results from the Gutenberg health study. J Affect Disord. 2020; 273:41-7. https://doi.org/10.1016/j.jad.2020.04.018.

67. Torske MO, Hilt B, Glasscock D, Lundqvist P, Krokstad S. Anxiety and depression symptoms among farmers: the HUNT study. Norway J Agromedicine. 2016;21(1):24-33. https://doi.org/10.1080/1059924x.2015.11 06375.

68. Rehm J, Shield KD. Global burden of disease and the impact of mental and addictive disorders. Curr Psychiatry Rep. 2019;21(2):10. https://doi.org/10.1 007/s11920-019-0997-0.

69. Paudel D. ABC Framework of Fear of COVID-19 for Psychotherapeutic Intervention in Nepal: A Review. PsyArXiv September 4 doi: https://doi.org/1 0.31234/osfio/9sj4a. 2020.

70. Schnell T, Spitzenstätter D, Krampe H. Compliance with Covid-19 public health guidelines: An attitude-behaviour gap bridged by personal concern and mandatory regulations. under review. 2021.

71. Saunders R, Buckman JEJ, Fonagy P, Fancourt D. Understanding different trajectories of mental health across the general population during the COVID-19 pandemic. Psychol Med. 2021:1-9. https://doi.org/10.1017/s00332 91721000957

72. Brooks SK, Webster RK, Smith LE, Woodland L, Wessely S, Greenberg N, et al. The psychological impact of quarantine and how to reduce it: rapid review of the evidence. Lancet. 2020;395(10227):912-20. https://doi.org/10.1016/ S0140-6736(20)30460-8.

73. Luo Y, Chua CR, Xiong Z, Ho RC, Ho CSH. A systematic review of the impact of viral respiratory epidemics on mental health: An implication on the coronavirus disease 2019 pandemic. Front Psychiatry. 2020;11:565098. https://doi.org/10.3389/fpsyt.2020.565098.

74. Rogers JP, Chesney E, Oliver D, Pollak TA, McGuire P, Fusar-Poli P, et al. Psychiatric and neuropsychiatric presentations associated with severe coronavirus infections: a systematic review and meta-analysis with comparison to the COVID-19 pandemic. Lancet Psychiatry. 2020;7(7):611-27. https://doi.org/10.1016/s2215-0366(20)30203-0

\section{Publisher's Note}

Springer Nature remains neutral with regard to jurisdictional claims in published maps and institutional affiliations.

Ready to submit your research? Choose BMC and benefit from:

- fast, convenient online submission

- thorough peer review by experienced researchers in your field

- rapid publication on acceptance

- support for research data, including large and complex data types

- gold Open Access which fosters wider collaboration and increased citations

- maximum visibility for your research: over $100 \mathrm{M}$ website views per year

At $\mathrm{BMC}$, research is always in progress.

Learn more biomedcentral.com/submissions 